Binghamton University

The Open Repository @ Binghamton (The ORB)

2014

\title{
An Aspect of Variable Population Poverty Comparisons: Does Adding a Rich Person to a Population Reduce Poverty?
}

Nicole Hassoun

Binghamton University--SUNY, nhassoun@binghamton.edu

Follow this and additional works at: https://orb.binghamton.edu/philosophy_fac

Part of the Philosophy Commons

\section{Recommended Citation}

Hassoun, Nicole, "An Aspect of Variable Population Poverty Comparisons: Does Adding a Rich Person to a Population Reduce Poverty?" (2014). Philosophy Faculty Scholarship. 14.

https://orb.binghamton.edu/philosophy_fac/14

This Article is brought to you for free and open access by the Philosophy at The Open Repository @ Binghamton (The ORB). It has been accepted for inclusion in Philosophy Faculty Scholarship by an authorized administrator of The Open Repository @ Binghamton (The ORB). For more information, please contact ORB@binghamton.edu. 
An Aspect of Variable Population Poverty Comparisons:

Does Adding a Rich Person to a Population Reduce Poverty? ${ }^{i}$

\section{Introduction}

Poverty indexes are essential for monitoring poverty, setting targets for poverty reduction, and tracking progress on these goals. No single paper could review, never mind evaluate, every proposed poverty measure in the literature. This paper suggests, however, that further justification is necessary for using the main poverty indexes in the literature in any of these ways (including those the World Bank makes easily available for empirical research). ${ }^{\mathrm{ii}}$ It does so by arguing that poverty should not decline with the mere addition of a rich person to a population. It, then, demonstrates that the standard poverty indexes do not satisfy this Weak Population Focus Axiom. Weak Population Focus is similar to, but less demanding than, what some have called the Poverty Focus and Nonpoverty-Invariance axioms (Subramanian, 2002; Paxton, 2003). iii So, it is significant that, unless the main poverty indexes in the literature are modified, they do not satisfy Weak Population Focus. In suggesting a modification of the standard indexes, this paper also isolates the reason why they fail to satisfy this axiom. ${ }^{\text {iv }}$

Unlike most work on poverty indexes that focuses on income as a proxy for poverty, this paper will not presuppose an answer to the question: "What is the proper basis for poverty measurement?" Poverty may, for instance, be deprivation in the space of welfare, capabilities, resources, or opportunities. To stay neutral on the proper basis for poverty measurement, this paper will refer to this basis as need. It will refer to whatever alleviates need or brings someone up higher above the poverty line as a good. Material goods, capabilities, opportunities, and welfare may be goods in this sense and they may alleviate need. 
Like most work on axiomatic poverty measurement, however, this paper will assume that there are better and worse answers to questions like: "What is poverty?" "How much poverty is there in a population?" and "Which population is poorer?" There may be room for multiple answers to these questions. What counts as poverty may, for example, be different in some contexts (e.g. in the US and Peru). ${ }^{v}$ Still, some things do not count as appropriate answers to the questions above. On any good account, for instance, most of the people living in the slums of New Delhi must count as poor. ${ }^{\mathrm{vi}}$

Moreover, for simplicity, this paper will assume that we know each individual's poverty level and that full interpersonal comparisons of need are possible. ${ }^{\text {vii }}$ That is, it assumes that questions like "How do individual identities and histories matter to their poverty?" and "Is poverty absolute or relative?" have already been answered. ${ }^{\text {viii }}$

Keeping these preliminaries in mind, the first part of this paper will consider methods for calculating poverty. It will argue that, when the main indexes in the literature are interpreted as providing a measure of the poverty in a population, these indexes violate an axiom or intuition that (Hassoun \& Subramanian, 2010) have called:

(1) Weak Population Focus: Poverty in a population is not reduced by changes in the nonpoor population which leave the distribution of goods amongst the poor unchanged. ${ }^{\text {ix }}$

The next section will consider why the main indexes in the literature violate this axiom if they are interpreted as measures of poverty in a population. It will then explain how it is easy to modify these indexes to avoid this problem.

\section{Axiom for a Plausible Account of Poverty in Variable Populations}

Before defending Weak Population Focus, it is important to distinguish between poverty in a population and related concepts like a population's poverty. ${ }^{\mathrm{x}}$ Considering two populations, $\mathrm{X}$ and $\mathrm{Y}$, saying there is more poverty in population $\mathrm{X}$ than in $\mathrm{Y}$ means: 
(1) $\mathrm{X}$ has more poverty than $\mathrm{Y}$ (that is: there is more poverty present in $\mathrm{X}$ than in $\mathrm{Y}$ )

This is not necessarily equivalent to the following statement about these populations' poverty:

(2) $\mathrm{X}$ is poorer than $\mathrm{Y}$ (that is: $\mathrm{X}$ is less wealthy overall than $\mathrm{Y}$ )

If 'poorer' is the converse of 'richer' like, e.g., 'worse' is the inverse of 'better'), (2) is equivalent to:

(3) $\mathrm{Y}$ is richer than $\mathrm{X}$.

But (3) is not equivalent to (1). Suppose $\mathrm{X}$ and $\mathrm{Y}$ only contain rich people but each person in $\mathrm{Y}$ is much richer than each person in $\mathrm{X}$. $\mathrm{Y}$ is richer than $\mathrm{X}$ but it is not the case that $\mathrm{X}$ has more poverty than Y. Neither contains any poverty at all.

Another way of seeing the distinction is to consider the following claims:

(4) Merely adding rich people to a population can make a population richer.

(5) Merely adding rich people to a population cannot reduce poverty.

(6) Making a population less poor is the same as making it richer.

(7) Making a population less poor is the same as reducing poverty.

Each of these claims is plausible on its own but, together, they are inconsistent:

Combining (4) and (6) we get:

(8) Merely adding rich people to a population can make a population less poor.

Combining (8) and (7) we get:

(9) Merely adding rich people to a population can reduce poverty.

This contradicts:

(5) Merely adding rich people to a population cannot reduce poverty.

The problem is that "less poor" is ambiguous - it may mean "more rich" or "contain(s) less poverty." The first definition is only clearly appropriate when we are considering $a$ population's poverty. ${ }^{\mathrm{xi}}$ Judgments about a population's poverty entail that if population A is 
poorer than B, B is richer than A. Saying there is more poverty in population A than B means A has more poverty than B but does not necessarily entail B is richer than A. Rather, this paper will argue that this claim is false.

It is also possible to distinguish between the poverty in a population and the average poverty. ${ }^{\text {xii }}$ The later will presumably divide the poverty in the population by the population size. Though, there are many possible measures of both the poverty in a population and the average poverty.

Keeping these distinctions in mind, it is possible to put this paper's point this way: it may be precisely because people have not distinguished carefully between the poverty in a population and related concepts like a population's poverty or the average poverty that most poverty indexes entail that merely adding a rich person to a population reduces poverty. This may be appropriate where we are concerned about a population's poverty (and "poorer" is the inverse of "richer") or the average poverty. It is not clearly true that merely adding rich people to a population will reduce the poverty in a population. Rather, this paper will argue that merely adding rich people to a population will not reduce the poverty in a population.

More precisely, this paper suggests adopting Weak Population Focus on which the poverty in a population cannot decline with additions to the rich population that leave the number and needs of the poor unchanged (though a population's poverty or the average poverty may decline with additions to the rich population that leave the number and needs of the poor unchanged). The rich may, of course, do a lot to alleviate poverty in a population. They might voluntarily or involuntarily give money (or other things) to the poor or their money (etc.) might trickle down to the poor. But, their mere existence in a population does not reduce poverty in a population. To illustrate the import of this axiom consider the following population: 


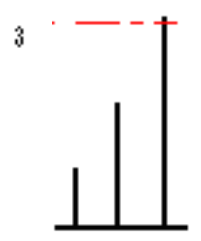

P1 P2 P3

Here the (dotted) poverty line is at three units of good. The first person, P1, has one unit of good, so needs two units to reach the poverty line. The second person, P2, has two units of good, so needs one more unit to reach the poverty line. The last person, P3, has more than three units of good, so is not poor. The Weak Population Focus Axiom suggests that simply adding more people who can meet their needs to the population does not reduce its poverty. So, adding an additional person P4 who can meet his or her needs to the population does not reduce the poverty in the population.

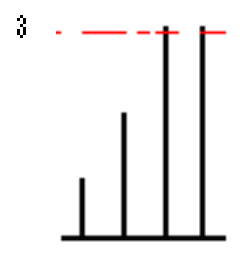

\section{P1 P2 P3 P4}

Nor would poverty in this population decline if $\mathrm{P} 4$ were much richer or there were additional rich people in it.

If some of the rich become poor, the poverty in a population might change. Even if some poor become rich at the same time, one might say poverty in the population has increased. This might be so if the newly poor are poorer than the newly rich were when they were poor or if there are more poor people.

As Amartya Sen puts it, it is also important to distinguish between descriptive indexes which are concerned with "the state of the poor"” and indexes intended to measure other things 
like a population's "potential ability to meet the challenge of poverty" (Sen, 1981, 190). The burden of poverty might, for instance, be less if rich people are just added to a population and nothing else changes. ${ }^{\text {xiii }}$ That is, it might be much easier to alleviate poverty by redistributing some goods from the rich to the poor. There may also be some respects in which adding rich people to a population makes it better (or worse) than the initial population. The new population might be better able to support the arts or sciences. Still, the mere addition of P4 does not in itself reduce poverty in this population. ${ }^{\text {xiv }}$

The intuition supporting Weak Population Focus is along the same lines as the intuition Sen expresses in objecting to the idea "that some increase in the income shortfall of the poor may be compensated by a sufficiently high rise in the income of the non-poor" (Sen, 1981, 190). He says "poverty is a characteristic of the poor, and a reduction of the incomes of the poor must increase the measure of poverty, no matter how much the incomes of the non-poor go up at the same time" (Sen, 1981, 190). Similarly, if poverty is a characteristic of the poor, an increase in the number of rich people should not alone reduce poverty in a population. A change in the number of rich people does not affect the poor any more than if the incomes of the rich increase. That is, adequate measures of poverty in a population will satisfy Weak Population Focus.

One might, however, object to Weak Population Focus by noting that, even though a measure of the poverty in a population is not necessarily a measure of how it is best to fulfill needs, these things are related. Perhaps the best explanation for intuitions about how it is best to meet need is that poverty in a population decreases when the only change is that more people who can meet their needs are added to the population. Consider an argument for this conclusion inspired by David Miller's work on how we should fulfill need. Miller is concerned with distribution according to need and claims that it is important, in deciding whom to help, to 
consider not only P1's claims vs. P2 and P3's claims but P1's claims against P4's claims (e.g. to what they need). He believes it is important to consider "the relative position of everyone" in determining whom we should aid in a population (Miller, 1999, 219). Miller thinks it is better to help those in the middle of the stack when there are a greater number of rich people around. Perhaps this is because poverty in the population with more rich people is worse. This might support the intuition that it is best to "equalize degrees of unmet need, which means distributing in favor of those in greater need until they are brought up to the same level as others" (Miller, 1999, 74).

Miller suggests that his intuition about how to distribute according to need underlies some empirical evidence from experiments in social psychology. In one experiment, there were two students one of whom needed extra money for books. Subjects had to decide how to split a set amount of money between them. Most subjects wanted to give the needy student enough to buy the textbooks before splitting the rest equally (Miller, 1999, 74). In another experiment, intended to mimic John Rawls' original position, subjects had to choose the rules for remuneration for work they were to perform. Most subjects chose to maximize average income subject to a floor constraint.

The empirical evidence does not support Miller's intuition about how to distribute according to need so one cannot use this evidence to argue that there is less poverty in $a$ population when the only change is that more people who can meet their needs are added to the population. The first experiment only provides evidence that sometimes people will try to help others meet their needs before distributing the remaining goods equally. The second experiment only provides evidence that most people want to provide a flat minimum for everyone (Frohlich \& Oppenheimer, 1992; Miller, 2001, 79). The results just show that people are concerned about 
need, not that "people will aim to equalize degrees of unmet need" (Miller, 2001, 74). ${ }^{\mathrm{xv}}$ The evidence does not support Miller's intuition about what distribution according to need requires (Hassoun, 2008). Hence, one cannot argue that the best explanation for why people share Miller's intuition about how we should meet need is that poverty in a population decreases when the only change is that more people who can meet their needs are added to the population. Unless there is a better reason to reject Weak Population Focus, we should accept it.

\section{Problems with the Existing Poverty Indexes and a Solution}

Many of the most common poverty indexes fail to satisfy the Weak Population Focus Axiom because these indexes normalize for population size by dividing by the total number of people in the population. These indexes are better interpreted as measures of the average poverty. Consider the simplest example -- the Headcount Index (H) which measures the proportion of people below the poverty line.

$$
H=q / n
$$

$n$ is the number of people in the population and $q$ the number of people who have an amount of good $y_{i}$ less than the amount necessary to reach the poverty line $z$. The problem is that adding a person above the poverty line to the population only increments $n$ and, so, poverty declines. Many other common poverty indexes fail to satisfy Weak Population Focus. The appendix demonstrates that this is so for Sen's Index and the Sen-Shorrocks-Thon index. Consider, here, just the Foster, Greer, Thorbecke ( $F G T)$ Index.

$$
F G T \text { 日 } 1 / n\left(\stackrel{q}{L}_{i \text { 日1 }}^{q} x_{i}^{a}\right)
$$


$x_{i}$ is the poverty gap of individual $i$ that is $\left(z \square y_{i}\right) / z$. Since ${\underset{i}{\text { ia }}}_{i}^{q} x_{i}^{a}$ aggregates the (weighted) poverty gaps of the poor only, it is unchanged by the mere addition of a rich person to a population. Because the addition of a rich person increases $n$, however, poverty declines on the $F G T$ when the only change is that a rich person is added to the population.

It, thus, seems that some justification is necessary for using the main poverty indexes in the literature in tracking poverty, setting poverty reduction targets, and so forth. If one is concerned to measure the poverty in a population, one should not use these indexes because they suggest poverty decreases with the mere addition of a rich person to a population. These indexes are better interpreted as providing measures of a population's poverty or the average poverty.

If the above indexes are interpreted as measuring a population's poverty or the average poverty, it is easy to see how to modify them to arrive at a measure of the poverty in $a$ population: Do not divide by the total number of people in the population. So, for instance, $H$

would just become $q$ and the $F G T$ would become the Aggregate Gap Index: $\mathbb{K}_{i \text { |⿴囗十 }}^{q} x_{i}^{a}$. Modifying the standard poverty indexes in this way will ensure that they satisfy Weak Population Focus.

Moreover, there seems to be some reason to accept a version of the Aggregate Gap Index as a measure of the poverty in a population. As least this is so if researchers can arrive at the correct account of individuals' poverty. The Aggregate Gap Index (with $a=1$ ) just adds up each individual's poverty. So it is plausible to hold that the Aggregate Gap Index yields the (total) poverty in a population..$^{\mathrm{xi}}$

III. Conclusion 
This paper has argued that the main poverty indexes in the literature may not be appropriate for tracking poverty, setting poverty reduction goals, and monitoring progress in meeting those targets. If the main poverty indexes in the literature are interpreted as measures of poverty in a population and are not modified, they unintuitively suggest that poverty in $a$ population declines with the mere addition of rich people. So some justification for using these indexes is necessary, especially since it is easy to modify them so that they satisfy Weak Population Focus. Moreover, assuming that researchers can arrive at the proper basis for poverty measurement, there is some reason to accept the Aggregate Gap Index as a measure of poverty in a population; there is reason to believe it tells us the sum-total amount of poverty in the population. In any case, further work on variable population poverty comparisons is pressing and important. 


\section{Appendix}

Consider the Sen-Shorrocks-Thon index (SST) index and Sen's index $(S)$ Here is the SST:

$$
\left.\mathrm{P}^{S S T}(a ; z)=K_{i \operatorname{1} 1}^{q}((2(n \square i)) \square 1) / n^{2}\right)\left(\left(z \square x_{i}\right) / z\right)
$$

Here is $S$ :

$$
\mathrm{P}^{S}(a ; \mathrm{z})=
$$

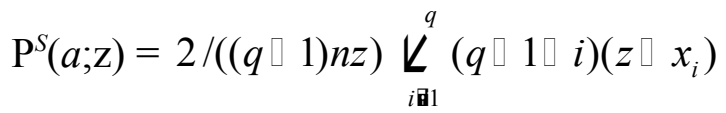

where $a$ is a vector of goods, $n$ is the number of people in the population, $q$ is the number of poor individuals in the population, $i$ is the order of the individuals in the distribution of goods - where $n$ has the most, and $x_{i}$ is the amount of good individual $i$ has.

It is easy to demonstrate that the $S S T$ and $S$ do not satisfy Weak Population Focus. ${ }^{\text {xvii }}$ It will suffice to present a counter-example. Consider the following vectors of goods $x$ and $y$ such that $y$ is derived from $x$ by the addition of a non-poor person. Without loss of generality, supposing an exclusive definition of poverty (that is that those with 0 good do not count as poor), and in line with the statement above, let $x=(0, z)$ and $\mathrm{y}=(0, z, z)$, where $z$ denotes the poverty line.

Proposition 1. The Sen-Shorrocks-Thon index (SST) does not satisfy Weak Population Focus. Proof.

We have: 


$$
\begin{gathered}
\mathrm{P}^{\mathrm{SST}}((0, z) ; z)=(2 * 1+1) / 2^{2} *(z / z)+(2 * 0+1) / 2^{2} *(0 / z)=3 / 4 \\
\mathrm{P}^{\mathrm{SST}}((0, z, z) ; z)=(2 * 2+1) / 3^{2} *(z / z)+0+0=5 / 9
\end{gathered}
$$

So according to the $S S T$, poverty in $y<x$. This violates Weak Population Focus.

Proposition 2. The Sen Index $(S)$ does not satisfy Weak Population Focus.

Proof:

We have:

$$
\begin{aligned}
& \mathrm{P}^{S}((0, z) ; z)=2 /(2 * 2 * \mathrm{z}) *(1 *(\mathrm{z}))=1 /(2 \mathrm{z}) * \mathrm{z}=1 / 2 \\
& \mathrm{P}^{S}((0, z, z) ; z)=2 /(2 * 3 * \mathrm{z}) *(1 * \mathrm{z})=1 /(3 \mathrm{z}) * \mathrm{z}=1 / 3
\end{aligned}
$$

So according to $S$, poverty in $y<x$. This violates Weak Population Focus. 


\section{Citations}

V. Aguirregabiria. 2006. "Sen-Shorrocks-Thon Index," Encyclopedia of World Poverty. Mehmet Odekon ed. Sage Publications: Thousand Oaks, CA.

G. Arrhenius. 2013. "Egalitarian Concerns and Population Change" Measurement and Ethical Evaluation of Health Inequalities. Ole Frithjof Norheim ed. Oxford University Press: Oxford.

W. Bossert. 1990. "Population Replications and Ethical Poverty Measurement." Mathematical Social Sciences. Vol. 19:143-158.

S. Chakravarty, S. Kanbur and D. Mukherjee. 2006. "Population Growth and Poverty Measurement." Social Choice and Welfare. Vol. 26, No. 3: 471-483.

J. A. L. Cranfield, Paul V. Preckel and Thomas W. Hertel. 2007. "Poverty Analysis Using an International Cross-Country Demand System.” World Bank Policy Research Working Paper 4285 World Bank: Washington D.C. Available at:

$<$ http://econ.worldbank.org/external/default/main? page $P K=64165259 \&$ theSite $P K=469372 \&$ piPK=64165421\& menuPK=64166322\&enti tyID=000158349_20070727110724>.

D. Donaldson and J. Weymark. 1986. "Properties of Fixed-Population Poverty Indices." International Economic Review. Vol. 27, No. 3: 667-688.

J. Foster, J. Greer, and E. Thorbecke. 1997. "A Class of Decomposable Poverty Measures.” The Measurement of Inequality and Poverty. S. Subramanian ed. Readers in Economics. Oxford University Press: Oxford.

A. Goldman. 1993. "The Psychology of Folk Psychology." Behavioral and Brain Sciences. Vol. 16: $15-28$.

A. Gopnik and H. Wellman. 1995. "Why the Child's Theory of Mind Really is a Theory." Mind and Language. Vol. 7: 145-71.

N. Hassoun. 2008. "Meeting Need.” Utilitas. Vol. 21: 250-275.

N. Hassoun. 2010. "Another Mere Addition Paradox? Some Reflections on Variable Population Poverty Comparisons.” WIDER Working Paper. 
N. Hassoun \& S. Subramanian. 2012. "An Aspect of Variable Population Poverty Comparisons." Journal of Development Economics. Vol. 98, No. 2: 238-241.

R. M. Hare. 1981. Moral Thinking. Clarendon Press: Oxford.

R. Kanbur. 2006. "Three Conundrums in Measuring Poverty with a Changing Population." Poverty Focus. UNDP International Poverty Center. Available at: $<\underline{\text { http://EconPapers.repec.org/RePEc:ess:wpaper:id:718>. }}$.

R. Kanbur and D. Mukherjee. 2007. "Premature Mortality and Poverty Measurement." Bulletin of Economic Research. Vol. 59, No. 4: 339-359.

A. Kundu and T.E. Smith. 1983. "An Impossibility Theorem on Poverty Indices." International Economic Review. Vol. 24, No. 2: 423-434.

D. Miller. 1999. Principles of Social Justice. Harvard University Press: Cambridge.

D. Parfit. 1984. Reasons and persons. Clarendon Press: Oxford.

J. Paxton. 2003. "A Poverty Outreach Index and Its Application to Microfinance." Economics Bulletin. Vol. 9, No. 2: 1-10.

T. Pogge. 2010. "Millions Killed by Clever Diluting of our Promises." CROP Poverty Brief/August 2010. Available at: <http://crop.org/>.

W. Rabinowicz. 2003. "The Size of Inequality and Its Badness - Some Reflections around Temkin's Inequality," Theoria 69, 60-84.

A. Sen. 1976. "Poverty: An Ordinal Approach to Measurement." Econometrica. Vol. 44, No. 2: 219-231.

A. Sen. 1981. Poverty and Famines: An Essay on Entitlement and Deprivation. Clarendon Press: Oxford.

A. Sen. 1997. "Poor, Relatively Speaking." The Measurement of Inequality and Poverty. S. Subramanian ed. Readers in Economics. Oxford University Press: Oxford.

S. Subramanian. 2002. "Counting the Poor: An Elementary Difficulty in the Measurement of Poverty." Economics and Philosophy. Vol. 18: 277-285.

S. Subramanian. 2005a. "Fractions versus Whole Numbers: On Headcount Comparisons of Poverty across Variable Populations." Economic and Political Weekly. Vol. 2005: 46254628.

S. Subramanian. 2005b. "Headcount Poverty Comparisons." International Poverty Centre One Pager No. 18, United Nations Development Programme: Brasilia, Brazil. 
S. Subramanian. 2006. "Poverty Measurement and Theories of Beneficence." Rights, Deprivation, and Disparity: Essays in Concepts and Measurement. Oxford University Press: Delhi.

United Nations Development Programme (UNDP). 2007. "Eradicate Extreme Poverty and Hunger." UNDP: New York. Available at: <http://www.mdgmonitor.org/goal1.cfm>.

K. Xu and L. Osberg. 1999. "An Anatomy of the Sen and Sen-Shorrocks-Thon Indices: Multiplicative Decomposability and Its Subgroup Decompositions." Dalhousie Working Paper Series. Dalhousie University: Halifax. 
${ }^{\mathrm{i}}$ The author would like to thank audiences at Stanford University, the National Center for Health Statistics, the United Nations' University's World Institute for Development Economics Research (WIDER) in Helsinki, Finland, the Department of Economics at Binghamton University, and the Workshop on Puzzles of Intergenerational Justice, at the Chaire Hoover, Louvaine-la-Nueve, Belgium. She would like to thank Peter Vallentyne, Terra Lawson-Remer, Luc Christensen, Richard Arneson, Augustin Faso, Susan Wolcott, Nicholas Vrousalis, Alex London, Teddy Seidenfeld, Kasper Lippert-Rasmussen, Axel Gosseries, Philippe van Parjis, John Mumma, Andreas Pape, Jon Pearson, Larry Temkin, two anonymous referees, and especially Subbu Subramanian, John Weymark and Efthymios Athanasiou for extremely helpful comments on previous drafts of the paper. Finally, she would like to thank Stanford's Center for Ethics in Society and the WIDER institute for their support during the course of this project.

${ }^{i i}$ For the World Bank's indicators, see: http://data.worldbank.org/indicator

iii It is the opposite of Nonpoverty Growth (Kundu \& Smith, 1983).

iv There are many articles on desirable properties of poverty indexes in fixed populations (Donaldson \& Weymark, 1986; Sen, 1976; Zeng, 1997). This paper takes up, and hopefully adds impetus to, the recent move to consider poverty indexes in variable population contexts (Kundu and Smith, 1983; Bossert, 1990; Subramanian, 2002, 2005a, 2005b; Chakravarty, Kanbur and Mukherjee, 2006; Kanbur and Mukherjee, 2007; Hassoun \& Subramanian, 2010).

${ }^{v}$ The first part of this paper will be less controversial if one assumes that poverty is absolute as opposed to relative. Poverty is relative (to some degree) if how much need someone in a population has is sensitive to how much other people have (Sen, 1997; Townsen, 1985). Whether poverty is relative or absolute may depend on the basis for poverty - whether it is subjective vs. objective welfare or resources etc. I owe thanks to an anonymous referee for suggesting this point.

${ }^{\mathrm{vi}}$ I focus throughout on indexes that recognize the possibility of unambiguously poor and non-poor segments of a population. That is, I do not propose adopting Weak Population Focus for fuzzy measures of poverty and the like.

${ }^{v i i}$ For one way of making such comparisons see: (Hare, 1981). Recent work on theory of mind may add to Hare's account by helping to explicate the process by which such comparisons are made. See: (Goldman, 1993; Gopnik and Wellman, 1995).

viii An individuals' poverty may be worse if that individual has been poor for a longer period of time or if the individual was richer (or poorer) in the past. It may also matter who is poor so that one of two people with identical histories could be poorer than another.

${ }^{\mathrm{ix}}$ In the economic literature on axiomatic poverty measurement it is customary to talk in terms of income so this generalization was not included in the initial version of this axiom, but it is appropriate to substitute "goods" for "income" here.

${ }^{\mathrm{x}}$ I am incredibly thankful to an anonymous referee for suggesting this way of clarifying the distinction and the puzzle that follows.

${ }^{\mathrm{xi}}$ Alternately we can derive a contradiction this way:

Combining (5) and (7) we get:

(10) Merely adding rich people to a population cannot make a population less poor.

Combining (10) and (6) we get:

(9) Merely adding rich people to a population cannot make a population richer.

This contradicts:

(4) Merely adding rich people to a population can make a population richer.

The analysis of the problem here is that "making a population less poor" is not clearly the same as "reducing poverty". The ambiguity still concerns the distinction between the poverty in a population and a population's poverty.

${ }^{\text {xii }}$ For related work on inequality measurement see: (Rabinowicz, 2003; Arrhenius, 2013).

xiii One reason to think potential ability to alleviate poverty matters in some cases (even if it does not map onto the poverty in a population) is this: If one were behind a Rawlsian veil of ignorance and did not know who one would be in a population, one might reasonably choose to enter a population with a smaller proportion of poor people.

${ }^{x i v}$ The idea here is different from Derek Parfit's mere addition paradox discussed below (Parfit, 1984).

${ }^{\mathrm{xv}}$ At another point, Miller also suggests subjects are balancing a concern for giving people their just deserts against a concern for need fulfillment. But, it is not clear that the evidence supports this contention (Hassoun, 2009).

${ }^{x v i}$ If goods have declining marginal needs satisfaction that is already taken into account in calculating individuals' needs (recall that individuals' needs are fixed before any aggregation takes place). The marginal need-satisfaction of a good for a person is the difference an additional unit of that good will make to how much need a person has. The marginal need satisfaction a person gets from a unit of necessary good declines the more units of necessary good the person already has. xvii The formulation of the $S S T$ comes from (Aguirregabiria, 2006). The formulation of the $S$ comes from (Sen, 1976). 